\title{
Poor trial design leaves gene therapy death a mystery
}

The gene therapy trial during which a 36-year-old Illinois woman died in July was inappropriately designed, experts said at the 17 September meeting of the government panel investigating her death.

Researchers affiliated with Seattle-based Targeted Genetics injected a gene therapy treatment into Jolee Mohr's right knee first in February and again on 2 July. On 24 July, Mohr died.

The immediate cause of her death was massive bleeding behind the kidneys from unknown causes, which led to the collapse of multiple organs. Her body was also overwhelmed by a fungal infection known as histoplasmosis, which can kill people with deficient immune systems.

Mohr had also been taking Humira (adalimumab), an injectable protein that eases the symptoms of rheumatoid arthritis throughout the body by blocking a protein called TNF-alpha. The gene therapy product being tested also blocks TNF-alpha, but it was expected to do so only in the affected knee.

"The study was poorly designed. If you're trying to test safety of a product, then by definition the person shouldn't be allowed to be on [another medicine in] that same class of product," Kyle Hogarth, a critical-care doctor at the University of Chicago, where Mohr died, told Nature Medicine after the Recombinant DNA Advisory Committee meeting. "What made her sick? Was it the Humira she was on or the gene [therapy] product? We'll never know."

There is no test proven to distinguish between the two medicines, although a test made by California-based Amgen may be able to do so. Both drugs suppress the immune system, and if the gene therapy product leaked out of the joint it may have tipped a precarious balance, allowing the fungal infection to overwhelm Mohr.

"If you don't have an assay, don't do the trial-that's my sense," Hildegund Ertl, who directs the Vaccine Center at The Wistar Institute in Philadelphia, said bluntly at the meeting.

These criticisms are off the mark, counters Stewart Parker, president and chief executive officer of Targeted Genetics. It is "good clinical practice" for people to be maintained on the medicines they are already taking when investigators introduce an experimental drug, Parker says. "If patients were denied current therapy, that would be considered unethical, as there is no guarantee in a safety study that benefit will be observed."

The purpose of local injection of the gene therapy is to treat joints that are unresponsive to injected proteins that affect the whole body, Parker adds. To treat resistant joints, she notes, "One would have to give massive doses of systemic therapy, which would lead to serious, significant side effects from systemic immunosuppression."

Meredith Wadman, Washington, DC

\section{Karolinska Institute under fire for controversial cancer report}

It's no surprise that access to new cancer drugs varies from country to country. But can this discrepancy be to blame for poor survival rates in some countries?

A controversial report from Sweden's famed Karolinska Institutet, which claims that access to the newest cancer drugs enhances survival, has triggered a spat between the report's authors and experts who say the report's conclusions are based on faulty analysis.

The report, first published in 2005 by the institute and updated in a June supplement in the Annals of Oncology, includes a chapter that examines the impact of a drug's 'vintage', the year it is first launched, on cancer survival in five European countries and concludes that cancer patients with access to the newest drugs live longer (Ann. Oncol. 18, iiil-iii77).

Michel Coleman, professor of epidemiology at the London School of Hygiene \& Tropical Medicine, says the researchers' methods are so flawed that the report should never have made it past the peer review process. "Just because the Karolinska institute is famous doesn't mean that everything that's published with its name on it is necessarily correct or laudable," he says .

In the same journal's September issue, Coleman points out that the report was funded by pharmaceutical giant Roche and lambasts the authors' methods (Ann. Oncol. 18, 1433-1435). For example, Coleman questions the report's use of survival data from the early 1990s and drug

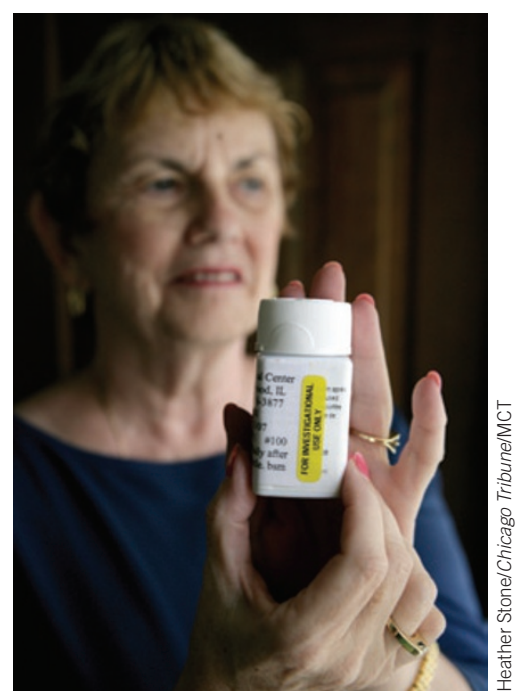

Quality of care: Can access to the newest cancer drugs improve survival?

access data from 2002 on. "How in the name of heaven can you draw any kind of causal conclusion that survival is somehow the result of the access to the drugs when the latter postdates the former by ten years?" he asks.

The UK's National Institute for Health and Clinical Excellence, the agency responsible for deciding which new drugs should be provided by the government, also publicly rebuked the authors. "This drug industry-sponsored report is flawed, inaccurate and directly contradicts itself in places," Andrew Dillon, the agency's chief executive, said in a statement in May.

Ulrik Ringborg, director of Karolinska's Cancer Center, would only say that the chapter has "tremendous methodological problems". "I cannot say they are wrong, I cannot say they are right because the methodology is not perfect."

The primary author of the controversial chapter, Columbia University economist Frank Lichtenberg, says the strong relationship between survival rates in different countries and drug vintage makes the conclusions more persuasive. "I quite frankly don't think that Coleman understands the techniques that we're using," Lichtenberg says.

Lichtenberg says he isn't surprised by the backlash, which he sees as a knee-jerk response. "Many people are highly critical of the pharmaceutical industry and anything that sounds like a positive message about the role of the pharmaceutical industry in society," he says.

Isabelle Durand-Zaleski, a health economist at the Hôpital Henri Mondor in Paris, notes that speedy drug access could be a marker of other factors that prolong life, such as better diagnostic facilities or a country's overall willingness to deal with disease. But the important thing, she adds, is that the debate will inspire more research.

Coleman couldn't agree more. "Critique is the substance of science," he says. "We'd never get anywhere if we all believed everything we saw in print."

Cassandra Willyard, New York 